\title{
Preoperative left ventricular ejection fraction and left atrium reverse remodeling after mitral regurgitation surgery
}

\author{
Lucia R Machado', Zilda M Meneghelo', David CS Le Bihan', Rodrigo BM Barretto', Antonio C Carvalho² \\ and Valdir A Moises ${ }^{2,3^{*}}$
}

\begin{abstract}
Background: Left atrium enlargement has been associated with cardiac events in patients with mitral regurgitation (MR). Left atrium reverse remodeling (LARR) occur after surgical correction of MR, but the preoperative predictors of this phenomenon are not well known. It is therefore important to identify preoperative predictors for postoperative LARR.

Methods: We enrolled 62 patients with chronic severe MR (prolapse or flail leaflet) who underwent successful mitral valve surgery (repair or replacement); all with pre- and postoperative echocardiography. LARR was defined as a reduction in left atrium volume index (LAVI) of $\geq 25 \%$. Stepwise multiple regression analysis was used to identify independent predictors of LARR.

Results: LARR occurred in 46 patients (74.2\%), with the mean LAVI decreasing from $85.5 \mathrm{~mL} / \mathrm{m}^{2}$ to $49.7 \mathrm{~mL} / \mathrm{m}^{2}$ ( $p$ <0.001). These patients had a smaller preoperative left ventricular systolic volume $(p=0.022)$ and a higher left ventricular ejection fraction (LVEF) $(p=0.034)$. LVEF was identified as the only preoperative variable significantly associated with LARR (odds ratio, 1.086; 95\% confidence interval, 1.002-1.178). A LVEF cutoff value of 63.5\% identified patients with LARR of $\geq 25 \%$ with a sensitivity of $71.7 \%$ and a specificity of $56.3 \%$.
\end{abstract}

Conclusions: LARR occurs frequently after mitral valve surgery and is associated with preoperative LVEF higher than $63.5 \%$.

Keywords: Mitral valve insufficiency, Mitral valve surgery, Left atrial remodeling, Left atrial volume

\section{Introduction}

Both left atrial enlargement and remodeling are compensatory mechanisms in patients with chronic severe mitral regurgitation (MR). These changes allow the left atrium to accommodate the regurgitant volume without increased pressure [1-3]. It is recognized that left atrial enlargement is a marker of major cardiovascular events such as atrial fibrillation, stroke, and death in patients with cardiac disease [4-8]. In patients with chronic severe MR, left atrial size seems to be an important predictor of outcome, either during

\footnotetext{
*Correspondence: vmoises@unifesp.br

${ }^{2}$ Escola Paulista de Medicina, Universidade Federal de São Paulo, São Paulo, SP, Brazil

${ }^{3}$ Disciplina de Cardiologia, Rua Napoleão de Barros, 715, São Paulo, SP CEP: 04024-002, Brazil

Full list of author information is available at the end of the article
}

conservative treatment or after mitral valve surgery [3,9-11]. A decrease in left atrial size, or reverse remodeling, has been observed after mitral valve surgery [12-17]. These prior studies included patients with different causes of MR, analyzed left atrial size using different techniques, and found different pre- and postoperative factors related to postoperative left atrial reverse remodeling (LARR). Different definitions of LARR after MR surgery have also been used; some considered any reduction value and others no more than 15\% [12-17]. Low values may be very sensitive and may not have great hemodynamic meaning. We hypothesized that larger postoperative LARR would represent a stronger hemodynamic impact by surgery and have different predictor factors. The objectives of our study were to assess the changes in left atrial size after surgery for MR and to verify the preoperative 
parameters that may be associated with or predictive of a reduction in left atrial volume index (LAVI) of at least $25 \%$.

\section{Methods}

\section{Patients}

We prospectively enrolled 62 patients with degenerative (prolapse or flail leaflet) chronic severe MR who were scheduled to undergo mitral valve surgery (repair or replacement). The ethical committee review board of both participating institutions approved the study, and all patients provided informed consent (Research Ethical Committee: Escola Paulista de Medicina and Instituto Dante Pazzanese de Cardiologia). Patients were excluded if they had functional or acute MR, associated moderate or severe disease of another cardiac valve, coronary artery disease, congenital heart disease, infective endocarditis, acute rheumatic fever, stage 2 or 3 systemic hypertension, or a past history of mitral-valve surgery. Patients who had greater than mild MR after surgery were also excluded. Pre- and postoperative assessment included the patients' clinical history, physical examination, electrocardiography, chest radiography, and echocardiography. Recommendations for coronary angiography and mitral-valve surgery (valvular repair vs. replacement) were made according to international guidelines $[18,19]$.

\section{Echocardiography}

All patients had a comprehensive transthoracic echocardiogram prior to surgery (Vivid7 ${ }^{\circ}$; GE Vingmed Ultrasound, Horton, Norway), using a 2-4 MHz multifrequential transducer. Echocardiography was repeated between 2 and 10 months after surgery. Patient position, echocardiographic imaging planes, and measures were performed as recommended by the American Society of Echocardiography [20]. Two experienced echocardiographers acquired and analyzed all images. The left ventricular diastolic and systolic diameters were measured using M-mode or 2-dimensional echocardiography. The left ventricular systolic volume, diastolic volume, and ejection fraction (LVEF) were obtained using the biplane Simpson method. The left atrial volume was estimated using the biplane area-length method and expressed in milliliters $(\mathrm{mL})$. LAVI was determined by dividing left atrial volume $(\mathrm{mL})$ by body surface area $\left(\mathrm{m}^{2}\right)$. LARR was defined as a reduction of $\geq 25 \%$ in LAVI on postoperative echocardiography.

The morphologic and functional characteristics of the mitral valve were analyzed to determine the etiology of each patient's disease. The severity of MR was estimated using the flow convergence method [21]. Severe MR was defined as a regurgitant volume $\geq 60 \mathrm{~mL} /$ beat and an effective regurgitant orifice area $\geq 0.40 \mathrm{~cm}^{2}$. For all measurements, diastole was defined as the beginning of the QRS complex, and systole was defined as the peak of the $\mathrm{T}$ wave in the same cardiac cycle. The final value of each variable was the mean of 3 measurements in different cardiac cycles.

\section{Statistical analysis}

Continuous variables are presented as mean values \pm standard deviation, and categorical variables as absolute numbers and percentages. The normal distribution of continuous variables was analyzed using the KolmogorovSmirnov test. The association between categorical variables was assessed using either Pearson's chi-square or Fisher's exact test. To compare preoperative and postoperative variables, the paired Student's t-test or the Wilcoxon test, were used. Comparison between groups with and without LARR was done using either Student's t-test or the Mann-Whitney test. Stepwise multiple regression analysis using the backward elimination method was used to determine preoperative variables associated with LARR. The Yolden criteria were used to identify the cutoff value of LVEF that predicted LARR $\geq 25 \%$ [22]. Intra- and interobserver variability was assessed by means of percentual difference between measurements, the paired t-test, and the Pearson correlation coefficient. The significance level of all tests was set at $5 \%$.

\section{Results}

The baseline characteristics of the patients are presented in Table 1. Thirty-four patients (54.8\%) underwent mitral

Table 1 Baseline patient characteristics

\begin{tabular}{lc}
\hline Variables & $\mathbf{n}(\%)$ \\
\hline Male sex & $37(59.7)$ \\
Body surface area $\left(\mathrm{m}^{2}\right)$; mean \pm SD & $1.73 \pm 0.19$ \\
Stage 1 systemic hypertension & $37(59.7)$ \\
Rhythm: & \\
$\quad$ Sinus & $50(80.6)$ \\
$\quad$ Atrial fibrillation & $12(19.4)$ \\
Functional class: & \\
$\quad$ II & $43(69.4)$ \\
Medications: & $19(30,6)$ \\
Diuretic & \\
ACE inhibitor & $54(84.4)$ \\
Beta blocker & $38(59.4)$ \\
Calcium channel blocker & $25(39.1)$ \\
Digoxin & $9(14.1)$ \\
Amiodarone & $9(14.1)$ \\
Aspirin & $1(1.6)$ \\
Oral anticoagulant & $13(20.3)$ \\
\hline ACE: angonsing & $3(4.7)$ \\
\hline
\end{tabular}

ACE: angiotensin converter enzyme; SD: standard deviation. 
valve repair and 28 (45.2\%) underwent valve replacement, using 19 biological and 9 mechanical prostheses. Surgical atrial reduction was not performed in any patients included in the study. In the postoperative evaluation, 52 patients were in sinus rhythm, and 10 in atrial fibrillation. Sixty $(98.8 \%)$ patients had a preoperative LAVI $\geq 40 \mathrm{~mL} / \mathrm{m}^{2}$. The LAVI decreased from a preoperative mean of $85.5 \mathrm{~mL} / \mathrm{m}^{2}$ to a postoperative mean of $49.6 \mathrm{~mL} / \mathrm{m}^{2}$ $(p<0.001)$; the mean reduction was $39 \%$. LARR was observed in $46(74.2 \%)$ patients.

Categorical variables such as sex, age $\geq$ or $<50$ years old, the presence or absence of systemic hypertension, functional class of I/II or III/IV, type of surgery performed (repair or replacement), postoperative mean diastolic gradient and preoperative cardiac rhythm (sinus or atrial fibrillation) were not significantly associated with LARR, with $p$-values ranging from 0.14 to 1.0. All echocardiographic variables, including LVEF, decreased significantly after surgery, but the difference in left ventricular systolic volume was not statistically significant (Table 2). Patients with LARR had smaller preoperative left ventricular systolic volume values and higher LVEF values $(p=0.022,0.034$, respectively); other preoperative variables were not significantly different between patients with or without LARR (Table 3). Stepwise multiple regression analysis revealed that LVEF was the only preoperative variable significantly associated with LARR (odds ratio, 1.086; 95\% confidence interval, 1.002-1.178). A cutoff value of $63.5 \%$ for preoperative LVEF identified patients with LARR $\geq 25 \%$ after surgery, with a sensitivity of $72 \%$ and a specificity of $56 \%$.

Analysis of intra- and interobserver variability showed a high and significant correlation in LAVI measures $(\mathrm{r}=0.97$; $p<0.0001)$ with a mean difference of $8.7 \%(p=0.10)$. The mean difference between the 2 LAVI measurements by the same observer was $9.3 \%(p=0.10)$ and the measurements were highly correlated $(\mathrm{r}=0.98 ; p<0.0001)$.

\section{Discussion}

We found that LARR occurs frequently after surgery for chronic severe MR and that preoperative LVEF is the

Table 2 Echocardiographic variables

\begin{tabular}{lccc}
\hline Variables & Before surgery & After surgery & $P$-value \\
\hline $\operatorname{LAVI}\left(\mathrm{mL} / \mathrm{m}^{2}\right)$ & $85.5 \pm 36.8$ & $49.7 \pm 25.1$ & $<0.001$ \\
$\operatorname{LVdD}(\mathrm{mm})$ & $61.0 \pm 5.3$ & $52.4 \pm 5.5$ & $<0.001$ \\
$\operatorname{LVsD}(\mathrm{mm})$ & $38.3 \pm 5.2$ & $35.3 \pm 6.0$ & $<0.001$ \\
$\operatorname{LVdV}(\mathrm{mL})$ & $133.8 \pm 40.1$ & $98.2 \pm 32.1$ & $<0.001$ \\
$\operatorname{LV} V(\mathrm{~mL})$ & $46.5 \pm 23.3$ & $41.6 \pm 19.8$ & 0.23 \\
$\operatorname{LVEF}(\%)$ & $66.1 \pm 7.5$ & $59.1 \pm 9.1$ & $<0.001$
\end{tabular}

Values given as mean \pm standard deviation.

LAVI: left atrium volume index; LVdD: left ventricle diastolic diameter; LVsD: left ventricle systolic diameter; LVdV: left ventricle diastolic volume; LVsV: left ventricle systolic volume; LVEF: left ventricle ejection fraction.
Table 3 Comparison of age and preoperative echocardiographic variables of patients with or without postoperative left atrium reverse remodeling

\begin{tabular}{lccc}
\hline Variable & $\begin{array}{c}\text { LAVI reduction } \\
(\mathbf{n}=\mathbf{1 6})\end{array}$ & $\begin{array}{c}\text { LAVI reduction } \mathbf{2 5 \%} \\
(\mathbf{n}=\mathbf{4 6})\end{array}$ & $\boldsymbol{p}$-value \\
\hline Age (years) & $50.3 \pm 17.3$ & $53.3 \pm 14.3$ & 0.42 \\
LAVI (mL/m²) & $77.3 \pm 39$ & $88.4 \pm 36$ & 0.15 \\
LVdD (mm) & $61,6 \pm 5.4$ & $60.8 \pm 5.3$ & 0.75 \\
LVsD (mm) & $39.8 \pm 5.0$ & $37.8 \pm 5.1$ & 0.25 \\
LVdV (mL) & $151 \pm 46$ & $128 \pm 37$ & 0.050 \\
LVsV (mL) & $60 \pm 28$ & $42 \pm 20$ & 0.022 \\
LVEF (\%) & $63 \pm 9.0$ & $67 \pm 6.7$ & 0.034 \\
RV (mL) & $88 \pm 27$ & $96 \pm 45$ & 0.88 \\
EROA (cm $\left.{ }^{2}\right)$ & $0.56 \pm 0.18$ & $0.60 \pm 0.24$ & 0.83 \\
\hline
\end{tabular}

Values given as mean \pm standard deviation.

EROA: effective regurgitant orifice area; LAVI: left atrium volume index; LVdD: left ventricle diastolic diameter; LVsD: left ventricle systolic diameter; LVdV: left ventricle diastolic volume; LVsV: left ventricle systolic volume; LVEF: left ventricle ejection fraction; RV: mitral valve regurgitant volume per beat.

only variable significantly associated with a postoperative LAVI reduction of at least $25 \%$.

The percentage of patients in our study with LARR after mitral valve repair or replacement is similar to other study populations previously described [12-17]. Many factors have been reported as determinants of LARR after mitral regurgitation surgery. These include MR etiology, patient age, preoperative LAVI, cardiac rhythm, mitral valve double dysfunction with predominant MR, systemic arterial pressure, diastolic mitral pressure gradient, postoperative reduction in left ventricle diastolic volume, and residual mitral regurgitation after surgery [13-17]. Prior studies differed from ours regarding the etiology of MR, the criteria used to define LARR, the techniques used to analyze left atrial size, and the statistical methods employed. In our study, a preoperative LVEF of $63.5 \%$ or higher identified those patients with at least 25\% LARR. This is interesting, since LVEF in MR is an important prognostic factor for postoperative LVEF and functional class, and a determinant for surgical correction in asymptomatic patients. A LVEF of $63.5 \%$ is close to the $60 \%$ recommended as the threshold for surgery in most guidelines and similar to the finding of a recently published study $[18,19,23,24]$.

Left atrial size in patients with chronic mitral regurgitation increases with the severity of the regurgitant volume and with the duration and progression of the disease [1-3]. Also influencing left atrial dilation, LVEF is known to deteriorate in patients with advanced MR, and diastolic dysfunction may occur [2,3]. As long as left atrial dilation persists or progresses, interstitial wall fibrosis and hypertrophy may develop and make reversal remodeling after surgery less likely [25-27] This may be a reason for the observed association of better preoperative LVEF 
with postoperative LARR in our study. After successful mitral-valve surgery with reduction in left ventricular volume, a decline in left ventricular filling pressure may have occurred, facilitating left atrium emptying and reverse remodeling.

As suggested by recent study, reducing mitralregurgitation volume may be an important determinant of LARR after mitral-valve intervention [23]. This may have been an important reason for the observed LAVI reduction in the present study, since all patients had severe preoperative regurgitant volume and no more than mild postoperative mitral regurgitation. These were predefined conditions to select patients for the study and may explain why both were not associated to LARR.

Some studies define LARR as a reduction of at least $15 \%$ in LAVI, but others do not define a cutoff value [12-17]. Failing to use a criterion, or using an inadequate cutoff value, may mean that the observed reduction fell within the range of inter- and intraobserver variability, or that the reduction had a small degree of clinical significance and consequently influenced both the quantitative identification of LARR and the determination of predictor factors. Our use of a reduction in LARR of at least $25 \%$ may have been important in the search for preoperative predictors. This value, higher than that used in other studies, was able to overcome the intra- and interobserver variability in left atrium volume measures and may therefore be more clinically relevant.

Considering the known association between increased left atrial size and cardiac events in patients with MR $[10,11]$ and the fact that early surgery may avoid excess left atrial dilation, it seems reasonable to point out that LARR after MR surgery may be beneficial. A recent large multicenter study using propensity-score matching found that early surgery in patients with MR due to flail leaflets was associated with less heart failure and lower mortality than medical management. However, there was no difference in atrial fibrilation, which is usually associated with a large left atrium [28]. In our study, preoperative atrial fibrillation was not associated with postoperative LARR; of 12 patients with preoperative atrial fibrillation, 2 recovered sinus rhythm after surgery. Another retrospective study did not find association between LARR and reduction of cardiovascular events, mortality and atrial fibrillation [29]. Further studies are needed to verify the prognostic benefits of LARR after mitral-valve surgery in patients with MR.

\section{Study limitations}

The time between postoperative echocardiography and surgery was relatively short in our study. Because of our method of patient selection, the results of this study may not be applicable to patients with MR from other causes, to patients with acute mitral insufficiency or to those with more than mild residual MR. Despite in our study the type of surgery was not related to LARR, a finding similar to other study [16], due to relative small number of patients and variations in type and size of prosthetic valves, we were not able to analyze separately patients who underwent mitral valve repair or replacement. Finally, 3-dimensional echocardiography was not used in our study, although it seems to be slightly more precise for determining LA volume compared with 2-dimensional echocardiography, and facilitates functional analysis.

\section{Conclusion}

In patients with primary chronic severe MR, LARR occurs frequently after valvular surgery and is associated with the preoperative LVEF higher than $63.5 \%$.

\section{Competing interests}

The authors declare that they have no competing interests.

\section{Authors' contributions}

LMR: study conception and designing, carried out patient selection and clinical assistance, data acquisition and analyzes and participated in the draft of the manuscript. ZMM: carried out patient selection and clinical assistance, and participated in the draft of the manuscript. DCSLB: Performance of echocardiographic studies with data acquisition, and interobserver variability. RBMB: Performance of echocardiographic studies with data acquisition, and intra and interobserver variability. ACC: study conception and designing, and critical review for important intellectual content. VAM: study conception and designing, data analyzes, participated in the draft of the manuscript, responsible for final changes and corrections, and submission to the journal. All authors read and approved the final manuscript.

\section{Author details}

${ }^{1}$ Instituto Dante Pazzanese de Cardiologia, São Paulo, SP, Brazil. ${ }^{2}$ Escola Paulista de Medicina, Universidade Federal de São Paulo, São Paulo, SP Brazil. ${ }^{3}$ Disciplina de Cardiologia, Rua Napoleão de Barros, 715, São Paulo, SP CEP: 04024-002, Brazil.

Received: 29 July 2014 Accepted: 17 October 2014

Published: 6 November 2014

\section{References}

1. Braunwald $E$, Awe WC: The syndrome of severe mitral regurgitation with normal left atrial pressure. Circulation 1963, 27:29-35.

2. Kihara Y, Sasayama S, Myazaki S, Onodera T, Susawa T, Nakamura Y, Fujiwara H, Kawai C: Role of left atrium in adaptation of the heart to chronic mitral regurgitation in conscious dogs. Circ Res 1988, 62:543-553.

3. Messika-Zeitoun D, Bellamy M, Avierinos JF, Breen J, Eusemann C, Rossi A, Behrenbeck T, Scott C, Tajik JA, Enriquez-Sarano M: Left atrial remodeling in patients with mitral regurgitation: methodological approach, physiological determinants, and outcome implications: a prospective quantitative Doppler-echocardiographic and electron-beam computed tomographic study. Eur Heart J 2007, 28:1773-1781.

4. Kizer JR, Bella JN, Palmieri V, Liu JE, Best LG, Lee ET, Roman MJ, Devereux RB: Left atrial diameter as an independent predictor of first clinical cardiovascular events in middle-aged and elderly adults: the strong heart study. Am Heart J 2006, 151:412-418.

5. Barnes ME, Miyasaka Y, Seward JB, Gersh BJ, Rosales AG, Bailey KR, Petty GW, Wiebers DO, Tsang TS: Left atrial volume in the prediction of first ischemic stroke in an elderly cohort without atrial fibrillation. Mayo Clin Proc 2004, 79:1008-1014.

6. Benjamin EJ, D'Agostino RB, Belanger AJ, Wolf PA, Levy D: Left atrial size and the risk of stroke and death. The Framingham Heart Study. Circulation 1995, 92:835-841.

7. Osranek M, Fatema K, Qaddoura F, Al-Saileek A, Barnes ME, Bailey KR, Gersh BJ, Tsang TS, Zerh KJ, Seward JB: Left atrial volume predicts the risk of atrial 
fibrillation after cardiac surgery: a prospective study. J Am Coll Cardio/ 2006, 48:779-786.

8. Laukkanen JA, Kurl S, Eränen J, Huttunen M, Salonen JT: Left atrium size and the risk of cardiovascular death in middle-aged men. Arch Intern Med 2005, 165:1788-1793.

9. Reed D, Abbott RD, Smucker ML, Kaul S: Prediction of outcome after mitral valve replacement in patients with symptomatic chronic mitral regurgitation: the importance of left atrial size. Circulation 1991, 84:23-34.

10. Le Tourneau T, Messika-Zeitoun D, Russo A, Detaint D, Topilsky Y, Mahoney DW, Suri R, Enriquez-Sarano M: Impact of left atrial volume on clinical outcome in organic mitral regurgitation. J Am Coll Cardiol 2010, 56:570-578.

11. Rusinaru D, Tribouilloy C, Grigioni F, Avierinos JF, Suri RM, Barbieri A, Szymanski C, Ferlito M, Michelena H, Tafanelli L, Bursi F, Mezghani S, Branzi A, Habib G, Modena MG, Enriquez-Sarano M: Left atrial size is a potent predictor of mortality in mitral regurgitation due to flail leaflets. Results from a large international multicenter study. Circ Cardiovasc Imaging 2011, 4:473-481.

12. Westenberg JJM, van der Geest RJ, Lamb HJ, Versteegh MIM, Braun J, Doornbos J, Roos A, van der Wall EE, Dion RAE, Reiber JHC, Bax JJ: MRI to evaluate left atrial and left ventricular reverse remodeling after restrictive mitral annuloplasty in dilated cardiomyopathy. Circulation 2005, 112:-1-437-|-442.

13. Antonini-Canterin F, Beladan CC, Popescu BA, Ginghina C, Popescu AC, Piazza R, Leiballi E, Zingone B, Nicolosi GL: Left atrial remodeling early after mitral valve repair for degenerative mitral regurgitation. Heart 2008, 94:759-764.

14. Cho DK, Ha JW, Chang BC, Lee SH, Yoon SJ, Shim CY, Cho JR, Kim JS, Choi EY, Rim SJ, Chung N: Factors determining early left atrial reverse remodeling after mitral valve surgery. Am J Cardiol 2008, 101:374-377.

15. Topal $A E$, Eren $M N$, Celik $Y$ : Left ventricle and left atrium remodeling after mitral valve replacement in case of mixed mitral valve disease of rheumatic origin. J Card Surg 2010, 25:367-372.

16. Song B, On YK, Jeon ES, Duk-Kyung K, Sang-Chol L, Park SW, Oh JK, Sung KI, Park PW: Atrioventricular reverse remodeling after valve repair for chronic severe mitral regurgitation: 1 year follow- up. Clin Cardiol 2010, 33:630-637.

17. Marsan NA, Maffessanti F, Tamborini G, Gripari P, Caiani E, Fusini L, Muratori M, Zanobini M, Alamanni F, Pepi M: Left atrial reverse remodeling and functional improvement after mitral valve repair in degenerative mitral regurgitation: a real-time- 3-dimensional echocardiography study. Am Heart J 2011, 161:314-321.

18. Bonow RO, Carabello BA, Chatterjee K, de Leon AC Jr, Faxon DP, Freed MD, Gaash WH, Lytle BW, Nishimura RA, O'Gara PT, O'Rourke RA, Otto CM, Shah PM, Shanewise JS, Smith SC Jr, Jacobs AK, Adams CD, Anderson JL, Antman EM, Faxon DP, Fuster V, Halperin JL, Hiratzka LF, Hunt SA, Page RL, Riegel B: ACC/AHA 2006 guidelines for the management of patients with valvular heart disease: a report of the American College of Cardiology/American Heart Association Task Force on Practice Guidelines (Writing Committee to Develop Guidelines for the Management of Patients With Valvular Heart Disease). Circulation 2006, 114:e84-e231.

19. Vahanian $A$, Baumgartner $H$, Bax J, Butchart E, Dion R, Fillipatos $G$, Flachskampf F, Hall R, Lung B, Kasprzak J, Nataf P, Torracca L, Weninck A: Guideline on management of valvular heart disease. The task force on the management of valvular heart disease of The European Society of Cardiology. Eur Heart J 2007, 28:230-268.

20. Lang RM, Bierig M, Devereux RB, Flachskampf F, Foster E, Pellika PA, Piccard MH, Roman MJ, Seward J, Shanewise JS, Solomon SD, Spencer KT, Sutton MS, Stewart WJ, Chamber Quantification Writing Group; American Society of Echocardiography's Guidelines and Standards Committee; European Association of Echocardiography: Recommendations for chamber quantification: a report from the American Society of Echocardiography's Guidelines and Standards Committee and the Chamber Quantification Writing Group, developed in conjunction with the European Association of Echocardiography, a branch of the European Society of Cardiology. J Am Soc Echocardiogr 2005, 18:1440-1463.

21. Zoghbi WA, Enriquez-Sarano M, Foster E, Grayburn PA, Kraft CD, Levine RA, Nihoyannopoulos P, Otto CM, Quinones MA, Rakowski H, Stewart WJ, Waggoner A, Weissman NJ: Recommendations for evaluation of the severity of native valvular regurgitation with two-dimensional and Doppler echocardiography. J Am Soc Echocardiogr 2003, 16:777-802.

22. Yolden WJ: Index for rating diagnostic tests. Cancer 1950, 3:32-35.
23. Grayburn PA, Foster E, Sangli C, Weissman NJ, Massaro J, Glower DG, Feldman T, Mauri L: Relationship between the magnitude of reduction in mitral regurgitation severity and left ventricular and left atrial reverse remodeling after MitraClip therapy. Circulation 2013, 128:1667-1674.

24. Tribouilloy C, Rusinaru D, Szymanski C, Mezqhani S, Fournier A, Lévy F, Peltier M, Ben Ammar A, Carmi D, Remadi JP, Caus T, Touati G: Predicting left ventricular dysfunction after valve repair for mitral regurgitation due to leaflet prolapse: additive value of left ventricular end-systolic dimension to ejection fraction. Eur J Echocardiogr 2011, 12(9):702-710.

25. Corin WJ, Murakami T, Monrad ES, Hess OM, Krayenbuehl HP: Left ventricular passive diastolic properties in chronic mitral regurgitation. Circulation 1991, 83:797-807.

26. Casaclang-Verzosa G, Gersh BJ, Tsang T: Structural and functional remodeling of the left atrium: clinical and therapeutic implications for atrial fibrillation. J Am Coll Cardiol 2008, 51(1):1-11.

27. Her A-Y, Choi E-Y, Shim CY, Song BW, Lee S, Ha J-W, Rim S-J, Hwang KC, Chang $B C$, Chung N: Prediction of left atrial fibrosis by speckle tracking echocardiography in mitral valve disease; a comparative study with histopathology. Korean Circ J 2012, 42:311-318.

28. Suri RM, Vanoverschelde J-L, Grigioni F, Schaff HV, Tribouilloy C, Avierinos JF, Barbieri A, Pasquet A, Huebner M, Rusinaru D, Russo A, Michelena HI, Enriquez-Sarano M: Association between early surgical intervention vs watchful waiting and outcomes for mitral regurgitation due to flail mitral valve leaflets. JAMA 2013, 310(6):609-616.

29. Hyllén S, Nozohoor S, Meurling C, Wierup P, Sjögren J: Left atrium reverse remodeling following valve surgery for chronic degenerative mitral regurgitation in patients with preoperative sinus rhythm: effects on long-term outcome. J Card Surg 2013, 28:619-626.

doi:10.1186/1476-7120-12-45

Cite this article as: Machado et al:: Preoperative left ventricular ejection fraction and left atrium reverse remodeling after mitral regurgitation surgery. Cardiovascular Ultrasound 2014 12:45.

\section{Submit your next manuscript to BioMed Central and take full advantage of:}

- Convenient online submission

- Thorough peer review

- No space constraints or color figure charges

- Immediate publication on acceptance

- Inclusion in PubMed, CAS, Scopus and Google Scholar

- Research which is freely available for redistribution 